\title{
LA EDUCACIÓN LATINOAMERICANA: UNA PROPUESTA DESDE LA COMPLEIDAD Y LA FILOSOFÍA
}

Leticia Correa Lozano*

\section{Introducción}

El devenir histórico de las sociedades nos ha enseñado a evitar una visión cerrada y parcializada en el análisis de los fenómenos sociales; consecuentes con este aprendizaje, debemos empezar ${ }^{1}$ a tener una conciencia más abierta a la problemática y complejidad de la realidad: "frente a un mundo cambiante y con nuevos desafíos se necesita de nuevas referencias interpretativas, que nos permitan apoderarnos de él de manera más efectiva" (Bravo en SHOPÍA 2, 2007: 35).

En este sentido, deberíamos ver a los sucesos histórico-sociales no como simples, predecibles o continuos, sino como problematizadores, contradictorios, inciertos y de múltiples interacciones entre sus muchos actores.

\footnotetext{
* Estudiante de Filosofía y Pedagogía, Universidad Politécnica Salesiana.
} 
A la complejidad de la sociedad hay que corresponderla con la formación de un pensamiento complejo, cosa que se logra primordialmente con la educación; proceso estructurado con base en la transmisión, transformación, reconstrucción y resignificación de los conceptos y de los hechos histórico-sociales. Educación y sociedad se nutren mutuamente.

Dentro de la sociedad (mundial) y su complejidad, nos encontramos con un tema en particular: Latinoamérica, que ha tenido un proceso de constitución y estructuración muy distinto de las otras sociedades, especialmente de las europeas. Precisamente, el propósito del presente trabajo es poner en evidencia los procesos de Latinoamérica en el espacio de la educación formal, según la teoría de la complejidad y examinados desde la perspectiva de Edgar Morin.

Para dicho fin, el trabajo se estructura en tres partes principales: primera, una breve perspectiva de los planteamientos teóricos de la complejidad; segunda, un poco de historia acerca de la constitución del 'ser' latinoamericano y su influencia en la forma y contenido de la educación; tercera, una tentativa de respuesta para mejorar la educación latinoamericana, sustentada en los presupuestos teóricos de la complejidad, con el fin de propender a lo que, en los últimos años, se llama interculturalidad. Y, finalmente, las conclusiones respectivas.

\section{La teoría de la complejidad: planteamientos y propuestas}

Vamos a empezar por donde lo han hecho varios autores de esta teoría, y el mismo Morin su estudio: la significación o significado de la palabra complejidad. 
La complejidad está asociada con confusión, incertidumbre y desorden, y casi contradice el conocimiento científico, el cual se encarga de desentrañar y eliminar la complejidad de los fenómenos que son objeto de su estudio, "el término complejidad no puede más que expresar nuestra turbación, nuestra confusión, nuestra incapacidad para definir de manera simple, para nombrar de manera clara, para poner orden en nuestras ideas" (Morín, 1997: 21).

La palabra complejidad está cargada de un sinnúmero de significados peyorativos $y$, en este sentido, no contribuye a la construcción de un pensamiento que permita el análisis de los fenómenos de la realidad, más bien parece limitar y nublar la reflexión científica.

Sin embargo, la complejidad es entendida por Morin de un modo distinto; para él la complejidad "es un tejido que presenta la paradoja de lo uno y lo múltiple, es un tejido de eventos, acciones, interacciones, retroacciones, determinaciones, azares, que constituyen el mundo fenoménico, por lo tanto la complejidad se presenta con matices de lo enredado, de lo inextricable, de la ambigüedad, la incertidumbre"(Cfr. Morín, 2005: 41).

Ahora bien, es necesario considerar que desde esta perspectiva de la complejidad ocupa un lugar primordial el 'pensamiento complejo'2, este comprende el orden a través de una idea más rica que la idea del determinismo, pues, además de esta, incluye las ideas de constreñimiento, estabilidad, constancia, regularidad, repetición, estructura e invariancia. El orden no es anónimo, sino que es productivo, tiene un origen condicionado y aleatorio, y depende de condiciones singulares y variables. Al pensamiento complejo y a la complejidad se le pueden atribuir las siguientes características: 
- El estatuto semántico y epistemológico del término complejidad no se ha concretado aún. Ahora bien, se puede afirmar que el discurso sobre la complejidad se generaliza cada vez más desde diferentes vías, pues así de múltiples son las vías de entrada a la complejidad.

- Aunque los autores tiene una opinión diferente en torno al término complejidad, casi todos distinguen entre complejidad y complicación; entre un problema cuantitativo y un asunto cualitativo.

- El pensamiento complejo sabe que la certidumbre generalizada es un mito y que es más potente un pensamiento que reconoce la vaguedad y la imprecisión que un pensamiento que la excluye inflexiblemente. Sus obligaciones con el conocimiento son mayores porque surgen de la lucidez, que muestra ausencia de fundamento en el conocimiento frente a la mitologización y el autoengaño de una idea de razón abstracta y omnipotente.

- Un pensamiento complejo nunca puede ser completo, porque es un pensamiento articulante y multidimensional. La ambición del pensamiento complejo es rendir cuenta de las articulaciones entre dominios disciplinarios fracturados por el pensamiento disgregador.

- El pensamiento complejo sabe que existen dos tipos de ignorancia. La del que no sabe y quiere aprender, $y$ de quien cree que el conocimiento es un proceso lineal, acumulativo, que avanza haciendo luz allí donde antes había oscuridad, ignorando que toda luz también produce, como efecto, sombras. No es posible partir metódicamente hacia el conocimiento impulsados por la confianza en lo claro y distinto, por ello es necesario partir en el 
conocimiento por la eliminación de las falsas claridades.

- El pensamiento complejo no desprecia lo simple, crítica la simplificación. En este sentido, la complejidad no es la simplificación puesta al revés ni elimina lo simple: la complejidad es la unión de la simplificación y la complejidad.

- El pensamiento complejo contiene en sí, como momentos correctores y a corregir, procesos que, aislados y librados a sí mismos, resultarían simplificadores. Los contiene íntegra y antagónicamente. El pensamiento complejo debe tener, por principio, su propio antagonista.

- El pensamiento complejo no rechaza al pensamiento simplificador, sino que configura sus consecuencias a través de una crítica a una modalidad de pensar que mutila, reduce, unidimensionaliza la realidad.

- El pensamiento complejo es lógico, pero también es consciente del movimiento irremediable del pensar y la imaginación que rebasan el horizonte lógico. El pensamiento complejo no excluye la linealidad sino que, muchas veces, la incluye en la visión y construcción de modelos recursivos para el conocimiento de la realidad.

- El pensamiento complejo piensa mediante macroconceptos; es decir, asociando conceptos atómicos separados por regla general, antagonistas a veces, pero que en su interrelación generan figuras complejas que, sin esa dinámica interactiva, se volatilizan y dejan de existir. 


\section{Complejidad y educación}

Indudablemente, la complejidad no puede dejar de lado una propuesta que enriquezca cualquier labor educativa, y nos ofrece ciertos lineamientos que parten y propenden, claramente, a la formación de un pensamiento complejo que nos ayude a entender mejor las relaciones e interacciones en la sociedad, y a comprender de 202 manera más

Actualmente, la educación se enfrenta a nuevas estructuras y nuevos planteamientos y desafíos que son parte de una sociedad en constante cambio y contradicción.

La globalización ha precipitado a la información, a la comunicación, a la sociedad en sí, a altísimos niveles de relativismo en nombre de la mal entendida (y practicada) libertad de pensamiento, del vivir el presente y el consumismo.

El lema que se maneja en la actualidad es de 'cómprelo, disfrútelo, tírelo'3, que da vía libre para cosificar a las personas, a la naturaleza, a todo tipo de interacción social, a utilizarla para el beneficio e interés individuales.

A breves rasgos, el anterior es el contexto en el que nos encontramos inmersos como aprendices, pero también como transmisores de conocimientos y maneras de conocer el mundo que, como hemos visto, se nos presenta con una vastísima gama de posibilidades para elegir (o no elegir), en la que el pensamiento simple es insuficiente para entender las nuevas relaciones e interacciones que se han generado en la cultura posmoderna.

Ahora bien, sabiendo que la educación es uno de los medios más formalmente estructurado y universal- 
mente aceptado (aunque criticado) en la socialización de conocimientos, es necesario que se exponga lo que el pensamiento complejo propone en lo referente a la construcción de un nuevo quehacer educativo.

A continuación se presenta un resumen de lo que Edgar Morin escribió en su libro Los Siete Saberes necesarios para la educación del futuro (2003)4.

\section{Las cegueras del conocimiento: el error y la ilusión}

- Es muy preocupante el hecho de que la educación permanezca ciega ante lo que es el conocimiento humano, sus disposiciones, sus imperfecciones, sus dificultades, sus tendencias tanto al error como a la ilusión, y no se dedique en absoluto a hacer conocer lo que es conocer.

- El conocimiento del conocimiento debe ser la primera necesidad a satisfacer en la preparación para afrontar los riesgos de error y de ilusión que no cesan de parasitar la mente humana. Se trata de armar cada mente para el combate vital en la conquista de la lucidez.

- Es necesario introducir y desarrollar en la educación el estudio de las características mentales y culturales del conocimiento humano, de sus procesos y modalidades, de las disposiciones tanto psíquicas como culturales que permiten arriesgar el error o la ilusión.

\section{Principios de un conocimiento pertinente}

- Existe un cuestionamiento capital: ¿Cuán necesario es promover un conocimiento capaz de abordar los 
problemas globales y fundamentales para inscribir allí los conocimientos parciales y locales?

- La supremacía de un conocimiento fragmentado en disciplinas impide operar el vínculo entre las partes y las totalidades; este debe dar paso a un modo de conocimiento capaz de aprehender los objetos en sus contextos, sus complejidades, sus conjuntos.

- Es necesario desarrollar la aptitud natural de la inteligencia humana para ubicar todas sus informaciones en un contexto y en un conjunto.

\section{Enseñar la condición humana}

- El ser humano es a la vez físico, biológico, psíquico, cultural, social, histórico. Es esta unidad compleja de la naturaleza humana la que hay que restaurar de tal manera que cada uno, desde donde esté, tome conocimiento y conciencia de su identidad compleja y, al mismo tiempo, de su identidad común con todos los demás humanos.

- La condición debe ser objeto esencial de cualquier educación.

- A partir de las disciplinas actuales es posible reconocer la unidad y la complejidad humanas reuniendo y organizando conocimientos dispersos en las ciencias de la naturaleza, en las ciencias humanas, la literatura y la filosofía, y mostrar la unión indisoluble entre la unidad y la diversidad de todo lo que es humano.

\section{Enseñar la identidad terrenal}

- El conocimiento de los desarrollos de la era planetaria y el reconocimiento de la identidad terrenal 
deben convertirse en los mayores objetivos de la educación.

- Es pertinente enseñar la historia de la era planetaria.

- Habrá que señalar la complejidad de la crisis planetaria que atraviesa el siglo XXI mostrando que todos los humanos, confrontados desde ahora con los mismos problemas de vida y muerte, viven en una misma comunidad de destino.

\section{Enfrentar las incertidumbres}

- La educación debería comprender la enseñanza de las incertidumbres que han aparecido en las ciencias físicas, en las ciencias de la evolución biológica y en las ciencias históricas.

- Se tendrían que enseñar los principios de estrategia que permitan afrontar los riesgos, lo inesperado, lo incierto, y modificar su desarrollo en virtud de las informaciones adquiridas en el camino.

- Es imperativo que todos aquellos que tienen la carga de la educación estén a la vanguardia de la incertidumbre de nuestros tiempos.

\section{Enseñar la comprensión}

- La comprensión es, al mismo tiempo, medio y fin de la comunicación humana. La tarea de la educación del futuro es la reforma de las mentalidades para el desarrollo de la comprensión.

- La comprensión mutua entre humanos es, en adelante, vital para que las relaciones humanas salgan de su estado bárbaro de incomprensión.

- Es necesario estudiar la incomprensión desde sus 
raíces, sus modalidades y sus efectos. Este estudio sería tanto más importante cuanto que se centraría no sólo en los síntomas, sino en las causas de las incomprensiones.

\section{La ética del género humano}

- La educación debe conducir a una antropo-ética que considere el carácter de la condición humana como el de ser a la vez individuo/sociedad/especie. En este sentido, la ética individuo/especie necesita que la sociedad ejerza control sobre el individuo y de este sobre la sociedad; es decir, la democracia; la ética individuo/especie convoca a la ciudadanía terrestre en el siglo XXI.

- La ética no se podría enseñar con lecciones de moral. Ella debe formarse en las mentes a partir de la conciencia de que el humano es al mismo tiempo el individuo que forma parte de una sociedad y de una especie.

- De allí se esbozan las dos grandes finalidades ético políticas del nuevo milenio: establecer una relación de control mutuo entre la sociedad y los individuos por medio de la democracia, y concebir a la humanidad como una comunidad planetaria.

- La educación debe contribuir no sólo a una toma de conciencia de nuestra tierra-patria, sino también permitir que esta conciencia se traduzca en la voluntad de realizar la ciudadanía terrenal.

\section{La construcción de 'lo latinoamericano':}

\section{una revisión histórica}

Sin duda, la construcción de lo latinoamericano tiene su base en el proceso histórico de la colonización o 
en el, mal llamado, 'Descubrimiento de América', y genera una cuestión identitaria muy amplia y compleja; no podemos decir, evidentemente, que nuestros antepasados indígenas se identificaban, en su gentilicio, como latinoamericanos.

Como ya se ha dicho, lo latinoamericano, o más bien el término Latinoamérica o América Latina, es causa de múltiples debates pertinentes a la identidad de la población de dicha región; sin embargo, en esta ocasión, no nos centraremos en el análisis del mencionado término y sus consecuencias, sino que lo asumiremos en el sentido de que hace referencia a los países que comparten una heredad cultural y constitución social comunes.

\section{Cambio de la dicotomía 'salvaje civilizado' a 'primitivo/civilizado'}

Partiendo de la anterior premisa, comenzaremos haciendo un pequeño análisis de la constitución de lo latinoamericano.

Ya hemos dicho que los rasgos de lo latinoamericano empezaron a constituirse a partir de la colonización; en 1492, Cristóbal Colón inició la apertura de un mundo "nuevo" para Europa en su proceso creciente de expansión. Este 'simple' hecho constituyó uno de los más vigorosos estímulos para el avance del proceso científico, técnico y económico, principalmente de España.

El 'nuevo' continente devino en un espacio inédito para las nuevas prácticas cognoscitivas y de sometimiento colonial: "1492 fue un momento crucial para la historia. Colón no sólo abrió posibilidades al creciente desarrollo de las fuerzas productivas de las principales potencias europeas, sino que viabilizó perspectivas más amplias para la ciencia” (Paredes, 1989: 15). 
El denominado 'Descubrimiento de América' representó un momento alto para la creación de una nueva realidad y de una nueva historia; en el que el sincretismo futuro de dos civilizaciones marcaría la esencia y el tipo de relaciones que caracterizarán al mundo moderno entre sociedades y regiones con distintos grados de desarrollo.

El supuesto 'descubrimiento', que afirmaba la superioridad de una cultura en relación con la otra, más por sujeción y dominio que por encuentro cultural, tal como fue el encuentro entre la cultura griega y la romana, generó en nuestras tierras la supresión y minimización de cualquier proceso histórico existente, y por ello jamás se pensó en una Historia latinoamericana contada desde Latinoamérica, ni en el diálogo cultural, y mucho menos en el planteamiento de una educación que ayude a producir pensamiento, sino que se impuso violentamente una concepción del mundo diferente a nuestra cosmovisión.

Europa anuló del todo las estructuras sociales, económicas y políticas existentes e hizo una interpretación de ellas desde una perspectiva limitada y focalizada, y, más aún, transformó a nuestra cosmovisión en una cosmovisión irracional, según el ideario social y científico de Europa; es decir, América Latina es salvaje no porque en ella no haya existido desarrollo científico, social y cultural, sino porque nuestra forma de conocer y explicar la realidad no se ajustaba a los cánones de la ciencia y la racionalidad que se manejaban en Europa.

La deslegitimación de la historia americana se da, precisamente, por la creencia de que lo europeo era superior a lo indígena. Evidentemente, este proceso de deslegitimación no se generó al interior de Latinoamérica, sino que respondió a estructuras sociales, teológicas 
y racionales de Europa. De esta manera, el hombre civilizado era el hombre europeo, que se presentaba como "la obra más acabada de la creación" (Rodríguez, 1991:21), al contrario del indígena del que se dudaba, incluso, de su propia humanidad.

Si el europeo era, segúnsus categorías, una obra perfecta y el latinoamericano, un ser sin alma, es decir, no una criatura de Dios, sino un salvaje que aspiraba a ser civilizado, esto es: a construirse y repensarse a imagen del europeo; por lo tanto, nada de su cultura, su ciencia y sus creencias valían la pena ser contadas y consideradas, sino sólo hasta que se asemejasen a la racionalidad y humanidad europeas.

La visión del hombre latinoamericano como salvaje -como nos indica Rodríguez- cambia, luego de algunas rupturas y sometimientos culturales, or una nueva dicotomía; primitivo/civilizado. Entendiendo como primitivos a los nuevos seres 'descubiertos' en una humanidad 'salvaje', pero reconociendo en ellos cierto eco de conocimiento (Cfr. ibíd.: 22). Conocimiento que evidentemente provenía del adoctrinamiento de los europeos.

Recién en el momento en el que al latinoamericano se le reconoce un bajísimo nivel de civilización es cuando se reconoce una continuidad histórica en Latinoamérica, y su historia empieza a ser contada, sin embargo, no desde Latinoamérica, sino desde una visión europea, puesto que la verdadera historia no tiene importancia en el discurso científico y racional de Europa.

Todo este proceso de deslegitimación se encarna, y empieza así la pérdida de conciencia histórica-crítica de y en Latinoamérica. 


\section{La escuela como aparato reproductor de la historia colonial}

Haciendo uso de la misma historia, evidenciamos que la escuela latinoamericana, entendida como cualquier proceso educativo formal, ha sido estructurada y construida basada en un modelo netamente europeo, en el que predominan matices medievales.

En esta historia se pueden identificar algunos aspectos que son comunes a todo el proceso educativo de Latinoamérica, y que corroboran a la escuela como un aparato reproductor de la historia contada desde Europa. A continuación se enumeran algunos de la autoría de Celina Lértora Mendoza.

1. Un modelo originario común, tanto en su estructura legal como en su estructura académica. Y aquí podemos mencionar a Salamanca como modelo de las universidades americanas.

2. Otro punto es la participación de agentes de cierta homogeneidad, cuyas conductas son comparables de acuerdo a un patrón de explicación histórica común.

3. En tercer lugar tenemos una serie de procesos socio políticos análogos que constituyen su entorno inmediato: las tensiones de la naciente sociedad criolla en los siglos XVI Y XVII, los idearios revolucionarios a fines del XVIII y principios del XIX, la anarquía y las luchas civiles y la organización republicana sobre modelos foráneos a mediados del siglo XIX ${ }^{5}$.

Es evidente que, debido a ese proceso de colonización y adoctrinamiento, la escuela latinoamericana no ha sido un lugar para crear y transmitir un pensamiento 
propio, sino que ha servido solamente como un aparato para mantener el estatus y la 'racionalidad europea'. Así, desde la colonización la escuela ha sido creada solamente para legitimar el sometimiento cultural, social, económico y cognitivo de los países latinoamericanos.

\section{Una nueva educación latinoamericana: una alternativa de respuesta}

La educación es la base de las transformaciones radicales en la sociedad, sean estas para bien o, por el contrario, nos lleven al retraso y al estancamiento intelectual; por ello, la mirada, en cuestiones de cambio social, debe fijarse principalmente en el quehacer educativo.

Como ya hemos dicho, a través de la historia, la educación en Latinoamérica ha estado en crisis permanente, no sólo por el salvataje colonial, sino también por la despreocupación de los estados en sus políticas educativas; lo que ha llevado a que la educación latinoamericana se encuadre dentro de los bienes de consumo que, no obstante, no la pusieron a la vanguardia, sino más bien la convirtieron en lo que podríamos llamar un desecho del consumismo.

Nuestra educación no responde a las necesidades ni a los grandes desafíos que la sociedad posmoderna y planetaria nos presenta, y no por incapacidad sino porque nos han acostumbrado y nos hemos acostumbrado a vivir bajo las pautas que el mundo occidental nos pone y que, de una u otra forma, nos impone.

No creemos que la educación del mundo occidental sea verdaderamente compleja. Es decir, no la asumimos como un modelo a seguir; en ella identificamos un pensamiento simplificante que no responde a los siete saberes de la educación que Morin plantea, y que los con- 
sideramos el ideal al que todo modelo educativo y pedagógico debe aspirar.

Ahora bien, ante el problema de que la educación en América Latina no coadyuva a la construcción de un pensamiento originalmente latinoamericano, nos planteamos una pregunta, que puede resultar obvia pero que, en cierto sentido, resulta compleja en sí misma: ¿Qué hacer ante esta situación?; ante las muchas respuestas que pueden surgir, y debido a la necesidad de tomar una posición para enfrentar este problema, optamos, en este caso, por la alternativa de vincular el pensamiento complejo con la filosofía, y específicamente con la filosofía latinoamericana.

\section{¿Una nueva filosofía?}

Lejos de las varias discusiones que se plantean alrededor de si existe filosofía latinoamericana o no, de si a la reflexión que se da (y se ha dado) en nuestras tierras debe llamarse o no filosofía, y de si debemos llamarnos o reconocernos como latinoamericanos, se plantea este tema como una interrogante, pues consideramos que la filosofía latinoamericana tiene ya un amplio recorrido histórico, y no debe ser vista como novedad; sin embargo, sí como una innovación al pensamiento europeo y logocentrista.

El hombre no puede entenderse sino solamente en la historia, como nos indica Zea (1945: 25): "La esencia de lo humano, aquello por lo cual el hombre es hombre, es la historia"; es decir, ninguno de nosotros, los latinoamericanos, podemos desconocer nuestra heredad cultural, tanto desde nuestros indígenas por vía directa como de los europeos mediante la colonización.

Kusch, en su libro América Profunda (1962), nos habla del concepto al que denomina fagocitación. La fago- 
citación produce, en América, la paradoja de ser alguien; es decir, mantenemos las estructuras impuestas sospechando de su debilidad y por eso cubrimos la falta de contenidos con un exceso de forma, demostramos pomposamente nuestra pulcritud porque sentimos el 'hedor' en lo más profundo de lo que somos.

El ser alguien es parte de la historia de la imposición. Como tal, utiliza la violencia, unas veces más sutilmente que otras, para mantener su vigencia, escondiendo su paradoja y excluyendo a todo lo opuesto. Pero esto sólo es posible en tanto se cuente con los objetos que nos aíslen de la naturaleza y repriman nuestro miedo a la ira divina.

Es decir, puede llevarse adelante entre la minoría que cuenta con los recursos necesarios para rodearse de objetos, pero demuestra su falsedad en aquellos sectores de la población que carecen de ellos. En los que quedan excluidos de la sociedad, la vida de ser alguien es imposible. Por eso, el excluido social recurre a la forma de vida originaria de la especie, el mero estar.

Entonces, la nueva filosofía latinoamericana deberá tener como principio el reconocimiento del legado histórico que nos dejaron los indígenas y los conquistadores españoles, integrando evidentemente nuevas corrientes de pensamiento, de tal manera que la filosofía que se genere esté abierta al cambio y al devenir histórico universal.

Se trata de una filosofía que haga una reflexión sobre las propias cuestiones latinoamericanas; una filosofía concreta que parta de la cotidianidad de la vida del hombre americano y que asumiendo otro tipo de reflexiones no haga de estas su horizonte teórico; Zea (Op. cit.: 27) dice al respecto: "lo que ha provocado el error ha sido el querer hacer de verdades circunstanciales verdades eter- 
nas, América no ha hecho otra cosa que adaptarse a las soluciones de la cultura europea".

Nuestras raíces, a pesar de la conquista, la imposición y la masacre, han permanecido de una manera latente; lo que significa que no se ha perdido del todo la identidad pre colonial, aunque hayan intentado hacerlo.

En este sentido, sería absurdo plantearse un tipo de filosofía que ignore por completo esa manera distinta de ver el mundo; que, aunque no encaje en los cánones científicos y filosóficos de la cultura europea, no por eso deja de estar llena de riqueza y sabiduría.

La realidad es que vivimos una identidad que nos viene dada tanto por lo europeo como por lo indígena. Así, la filosofía que se propone es una en la que se integren estas dos realidades históricas, que reconozca nuestro pasado, se encarne en nuestro presente y se proyecte al futuro.

No se trata solamente de hacer una interpretación al estilo occidental, sino de hacer una filosofía que sea originalmente latinoamericana, porque como dice Leopoldo Zea: "Los problemas de la filosofía no son, a fin de cuentas, sino problemas que plantean al hombre, la naturaleza y con los otros" (Cfr. ZEA, 1969: 34).

Entonces, la originalidad de esta propuesta es que, aunque utilice ciertas categorías europeas, su reflexión es diferente, porque es una interpretación de la realidad concreta de América Latina, que parte de los mismos latinoamericanos, de la cotidianidad de su vida, integrando su presente y su heredad cultural.

\section{Una educación intercultural}

Una de las características principales de la era planetaria es la aparición de nuevas culturas que se amalgaman con las ya existentes; por lo tanto, resulta ilógico 
pensar en la posibilidad de mantener guetos en la sociedad, mas si de lo que se trata es de mundializar nuestras relaciones.

Especialmente dentro del mundo latinoamericano, el término más utilizado para indicar estas relaciones entre culturas, es la interculturalidad.

Intercultural es un término que, como los que hemos presentado aquí, no esta exento de discusiones; sin embargo, por motivos de tiempo y espacio, lo entenderemos como la "cohabitación de culturas con sus diferencias y sus contradicciones" (Garcés, en Alteridad 5, 2008: 7).

En adelante, es oportuno enfocarnos en los problemas que son prioridad dentro de la educación latinoamericana.

- La cuestión identitaria: debido a los procesos históricos que ya mencionamos, Latinoamérica parece desconocerse a sí misma y no encontrar su lugar a nivel de pensamiento. De lo que se trata, entonces, es que a partir de la educación se logre interiorizar nuestras raíces, tanto andinas como europeas, $y$, a partir de ello, proyectar y vivir una identidad que elimine cualquier tipo de racismo, xenofobia, discriminación y sometimiento intelectual. Esto es lo que Morin llama diversidad; es decir, me reconozco diferente de los demás, me presento al mundo desde una visión específica, que me identifica, que me da mi ser, pero que también es abierta y tolerante con el «otro», que reconoce otras identidades, otras costumbres, que pueden enriquecer la mía. No se trata de un simple sincretismo, se trata de abrirse a lo que es diferente de mi yo, a un 'alter' que lo identifico y lo reconozco como un Tú.

- El hombre cosmopolita: las características de la sociedad planetaria y posmoderna nos plantean 
nuevos retos que no podremos enfrentarlos solamente como individuos, sino como 'ciudadanos del mundo'. Sólo reconociendo lo incierto, lo incomprensible y lo impredecible de las relaciones sociales y humanas, entenderemos nuestra realidad. Latinoamérica es un espacio que ha sido marcado por la implantación de modelos (económicos, políticos, educativos) que, en primer lugar, no responden a nuestra realidad, y, segundo, de los que poco o nada se conocen. A pesar de la masificación de los medios y de la información, no se tiene una conciencia que nos permita discriminar los mensajes que segundo a segundo transitan por la red social. La labor de la educación es, entonces, formar una conciencia crítica enfocada en el análisis e innovación de los hechos sociales, que nos permita tener una visión más amplia de lo que pasa en el mundo y que, por lo tanto, haga que nuestras propuestas tengan siempre esa aspiración de universalización; es decir, que sean para el mundo.

\section{Conclusiones}

La escuela es uno de los principales medios de transmisión y asimilación de conocimientos; en Latinoamérica, esta no debe servir a un modelo europeo indiscriminadamente planteado, sino convertirse en un medio de liberación que genere un pensamiento que responda mucho más a nuestra realidad.

En ese sentido, la escuela debe convertirse en un espacio en el que se siembre la semilla de un nuevo pensamiento que, si bien no esté desligado de la herencia cultural europea, necesite incorporar en su propuesta aquella historia y cultura indígenas que tienen una riqueza intelectual muy grande, y que, de una u otra forma, mar- 
can también nuestra forma de ser, de actuar y de sentir. Con este propósito debe iniciarse la tarea de lograr un pensamiento latinoamericano que parta de una real y verdadera conciencia histórica.

La complejidad, por sus planteamientos teóricos, se muestra en consonancia con el ideal de educación que todos queremos, una educación que reconozca la diversidad y que nos prepare para enfrentar los nuevos retos que seguramente seguirán surgiendo en esta era planetaria.

Es trabajo y compromiso de todos luchar siempre por la transformación de la sociedad y especialmente de la educación.

\section{Notas}

1 Se dice 'empezar' porque es un llamado a todas las personas a despabilarnos y tener una conciencia mucho más crítica de los fenómenos sociales, a tener una participación más activa en el cambio, a ser más propositivos, más argumentados.

2 Esta perspectiva del pensamiento complejo pertenece a la astucia de Edgar Morin, lo que se presenta en este artículo como pensamiento complejo es tomada de la obra anteriormente citada. Cfr. Ibíd., MORIN, Edgar, y otros, p. 45 - 54.

3 Este es el eslogan que Bauman le otorga a la sociedad de consumo, el cual no sólo hace referencia a las relaciones que los 'consumidores' hacemos con los objetos que adquirimos, sino que se aplica también a todo tipo de relación humana y social que establezcamos. BAUMAN, Zygmunt, Vida de Consumo, Fondo de Cultura Económica, Primera Edición en español, México, 2007, p. 135.

4 Como se ha dicho ya en el texto, se presenta un resumen de los siete saberes que Morin plantea en su libro. Cfr. MORIN, Edgar, Los Siete Saberes necesarios para la educación del futuro, Grupo Santillana S.A., UNESCO, Quito, Ecuador,2003, p. 17 - 21.

5 Cfr. MENDOZA, Celina Lértora: «Lineamientos para una historia de la universidad Latinoamericana», en: Cuadernos No 12, FHYCSUNJu, 2002. http://redalyc.uaemex.mx/pdf/185/18501505.pdf. 6 de marzo, 2010. 


\section{Bibliografía}

BAUMAN, Zygmunt

2007 Vida de Consumo, México: Fondo de Cultura Económica. BRAVO, Pedro

2007 El Sujeto en la Educación, en: SHOPÍA, colección de Filosofía de la Educación, n. 2, Quito, Ecuador, Universidad Politécnica Salesiana, Abya-Yala, junio.

GARCÉS, Fernando

2008 Interculturalidad, Política y Educación: panoramas y enfoques. En Alteridad: Revista de Ciencias Humanas, Sociales y de la Educación, n. 5, Ecuador, Universidad Politécnica Salesiana, Abya-Yala, noviembre.

KUSCH, Rodolfo

1962 América Profunda. Buenos Aires, Argentina: Editorial Hachette.

MENDOZA, Celina Lértora

2002 Lineamientos para una historia de la universidad Latinoamericana, en: Cuadernos No 12, FHYCS-UNJu, http:// redalyc.uaemex.mx/pdf/185/18501505.pdf, 6 de marzo, 2010.

MORIN, Edgar

1997 Introducción al Pensamiento Complejo. Barcelona, España: Editorial Gedisa.

MORIN, Edgar

2003 Los Siete Saberes necesarios para la educación del futuro. Quito, Ecuador: Grupo Santillana S.A., UNESCO.

MORIN, Edgar, y otros

2005 Educar en la Era Planetaria. "El pensamiento complejo como método de aprendizaje en el error y la incertidumbre humana”. Quito, Ecuador: Grupo Santillana, UNESCO.

PAREDES, Domingo

1989 Ecuador: Ciencia y Tecnología Precolonial. Quito, Ecuador: Editorial El Duende.

RODRÍGUEZ, Omar

1991 Etnias, Imperios y antropología. Caracas: Editorial FACES/ UCV.

ZEA, Leopoldo

1945 En torno a una filosofía Latinoamericana. México: Fondo de Cultura Económica. 
ZEA, Leopoldo

1969 La Filosofía Americana como Filosofía sin Más. México: Siglo XXI Editores. 